Received Date : 27-Jan-2016

Revised Date : 11-May-2016

Accepted Date : 15-Aug-2016

Article type : Original Manuscript

\title{
A national analysis of trends, outcomes and volume-outcomes relationships in thyroid surgery
}

SAR Nouraei ${ }^{1,2}$, JS Virk ${ }^{3}$, SE Middleton ${ }^{4}$, P Aylin' ${ }^{5}$, A Mace ${ }^{6}$, F Vaz ${ }^{7}$, H Kaddour ${ }^{8}$, A Darzi ${ }^{9}$, NS Tolley ${ }^{10}$

Affiliations:

${ }^{1}$ Speciality Registrar, Department of ENT Surgery, University College Hospital, London, UK

${ }^{2}$ National Institute for Health and Care Excellence (2013) Scholar, London, UK

${ }^{3}$ Speciality Registrar, Department of ENT Surgery, Royal London Hospital, London, UK

${ }^{4}$ Head of Innovation, Dr Foster Intelligence Ltd, Dorset Rise, London, UK

${ }^{5}$ Professor, Dr Foster Unit at Imperial College, Department of Primary Care and Public Health, Imperial College London, London, UK

${ }^{6}$ Consultant, Department of ENT Surgery, Charing Cross Hospital, London, UK

${ }^{7}$ Consultant, Department of ENT Surgery, University College Hospital, London, UK

This article has been accepted for publication and undergone full peer review but has not been through the copyediting, typesetting, pagination and proofreading process, which may lead to differences between this version and the Version of Record. Please cite this article as doi: 10.1111/coa.12730

This article is protected by copyright. All rights reserved. 
${ }^{8}$ Consultant, Department of ENT Surgery, Barking Havering \& Redbridge NHS Trust, Romford, UK

${ }^{9}$ Professor, Academic Surgical Unit, Department of Surgery \& Cancer, Imperial College Healthcare Trust, St Mary's Hospital, London, UK

${ }^{10}$ Consultant, Department of ENT Surgery, St Mary's Hospital, London, UK

Corresponding Author: SAR Nouraei BChir PhD FRCS, Department of ENT Surgery,

University College Hospital NHS Foundation Trust, London, UK. Email: RN@cantab.net

Source of Funding: Nil

Running head: National Analysis of Thyroid Surgery

Presented at the Prize session of the British Association of Endocrine and Thyroid Surgeons Annual Scientific Meeting, 8 January 2015, Liverpool, UK.

\section{ABSTRACT}

Objectives: Thyroid conditions are common and their incidence is increasing. Surgery is the mainstay treatment for many thyroid conditions, and understanding its utilisation trends and morbidity are central to improving patient care.

This article is protected by copyright. All rights reserved. 
Design: An N=near-all analysis of the English administrative dataset to identify trends in thyroid surgery specialisation, volume-outcome relationships, and the incidence and risk factors for short- and long-term morbidity.

Main outcome measures: Between 2004 and 2012, 72594 patients underwent elective thyroidectomy in England. Information about age, sex, morbidities, thyroid disease and surgery, adjuvant treatments, and complications including hypocalcaemia and vocal palsy were recorded.

Results: Mean age at surgery was $49 \pm 30$ and a female predominance $(82 \%)$ was observed. Most patients underwent hemithyroidectomy (51\%) or total thyroidectomy (32\%). Patients underwent surgery for benign (52.5\%), benign inflammatory $(21 \%)$, and malignant $(17 \%)$ thyroid diseases. Thyroid surgery grew by $2.9 \%$ a year and increased in specialization. Increased surgeon volume significantly reduced lengths of stay: the proportion of length of stay outliers fell from $11.8 \%$ for patients of occasional thyroidectomists ( $<5$ per year) to $2.8 \%$ for patients of high-volume surgeons ( $>50$ thyroidectomies a year). Post-discharge vocal palsy and hypocalcaemia occurred in $1.87 \%$ and $1.58 \%$ of cases respectively. High-volume surgeons had a reduced incidence of vocal palsy and volumes $>30$ were consistently protective.

Conclusions: Thyroid surgery is increasingly specialised. High-volume surgeons achieve lower complications rates, including lower vocal palsy rates, and length of stay.

This article is protected by copyright. All rights reserved. 
Keywords: Thyroid; Surgery; Health Informatics; Volume-outcome

\section{INTRODUCTION}

Thyroid diseases are common and the frequency with which they are identified is rising. ${ }^{1}$ With increasing availability of sensitive and specific radiological, ${ }^{2}$ cytological, biochemical, and genetic diagnostic tests, ${ }^{2-5}$ treatment decisions are increasingly supported by precisely stratified information about disease-specific risk and prognosis. Recognising that most thyroid conditions, including most cancers, ${ }^{2}$ carry excellent prognoses and given that in many cases treatment involves surgery, understanding and minimising surgical morbidity has long been a central consideration in reaching finely-balanced multidisciplinary treatment recommendations. ${ }^{6}$ This is reflected in the Calman-Hine report of 1995 and the subsequent NHS Cancer Plan, which strongly outlined a direction of travel towards multidisciplinary team working and specialisation of thyroid surgery within high-volume centres. ${ }^{7-8}$

More recently, thyroid surgery came to be included among the first group of specialties for which surgeon-level outcomes were published in England. 9 The principal current method of auditing thyroid surgery quality is the British Association of Endocrine and Thyroid Surgeons' (BAETS) national registry which at the last audit collected information about fewer than $30 \%$ of thyroidectomies performed in England and contained no linkages, which meant that it could not provide any information about long-term complications and 
outcomes. ${ }^{10}$ We undertook a national analysis of trends in utilisation, casemix, specialisation, and outcomes of thyroid surgery in England using the national administrative dataset.

\section{MATERIALS \& METHODS}

Case identification

Records of patients who underwent thyroidectomy in England between 2004 and 2012 were obtained from Hospital Episode Statistics (HES) dataset using an informatics algorithm derived from the tenth edition of the International Classification of Diseases (ICD10) ${ }^{11}$ and the Office of Population Censuses and Surveys (OPCS) manual of interventional procedures (Figure 1). ${ }^{12}$

Data definitions

Thyroid diagnoses were stratified as benign, benign inflammatory, benign neoplasm and malignant neoplasm, and the latter group also contained lymphomas. Surgery was divided into isthmusectomy, hemithyroidectomy, total thyroidectomy, subtotal thyroidectomy and unclear-type thyroidectomy. A completion thyroidectomy was designated if a second thyroidectomy was undertaken within 120 days of the index thyroidectomy. Concomitant 
neck surgery, which was defined as either a neck dissection or neck node sampling, was also assigned to the index surgery if it was undertaken at, or within, 120 days of it.

Patient morbidity was stratified using the ICD-based Charlson comorbidity index. ${ }^{13}$ Postoperative disorders of calcium homeostasis were defined as postoperative if they were coded in the index thyroidectomy and as post-discharge if they were identified during a subsequent admission. Vocal palsy was similarly defined as postoperative or post-discharge, and vocal treatment was defined as medialisation thyroplasty, speech therapy, or arytenoidectomy. It excluded tracheal resection, tracheal stent placement, or tracheostomy (Figure 1). Follow-up was calculated as the most recent attendance at outpatients or a hospital admission, and time from index procedure to the occurrence of specific events such as placement of gastrostomy tube, emergency admission to hospital, hospital admission with acute lower respiratory tract infection, or in-hospital death were used as actuarial outcome variables.

Overall, over $98 \%$ of all thyroidectomies were performed by general surgeons or by ear nose and throat surgeons (Figure 2). The remaining operations were performed under the care of a range of specialties and were excluded from further analysis. Surgeon volume was calculated by dividing the total number of thyroidectomies performed by the surgeon to the total number of years the surgeon performed thyroidectomies. Specialism ratio was defined as the ratio of the number of thyroidectomies performed by surgeons who performed more than 50 thyroidectomies per year (high-volume surgeons) to the number of thyroidectomies 
performed by surgeons who performed fewer than 10 thyroidectomies per year (lowvolume surgeons). A multiple regression model was constructed to calculate predicted length of stay given patient and treatment characteristics, and residual length of stay was the difference between a patient's actual and predicted length of stay. Tukey's method for outlier detection was used to identify patients who had outlying prolonged lengths of stay. 14

\section{Ethical approval}

We have permission from the National Information Governance Board under Section 251 of the NHS Act 2006 (formerly Section 60 approval from the Patient Information Advisory Group) to hold confidential data and analyse them for research purposes (ref PIAG 2-05 (d)2007). We have approval to use them for research and measuring quality of delivery of health care, from the South East Ethics Research Committee (Ref: 10/H1102/25).

Data analysis

Continuous variables were expressed as means with standard deviation and binomial variables were expressed as a percentage. Logistic regression was used to investigate relationships between risk factors and complications occurring during the same hospital admission as the index thyroidectomy. Kruskal-Wallis was used to investigate the 
relationship between surgeon volume and different treatment-related complications, as well as the relationship between surgeon volume and proportion of patients with outlying lengths of stay. Analysis of variance was used to interrogate the relationship between surgeon volume and length of stay. Analyses were performed using MedCalc (MedCalc Software bvba, Acacialaan, Belgium).

\section{RESULTS}

Patient characteristics

Over the study period 72,594 patients with a mean age of $49 \pm 30$ and with a strong female predominance of $82 \%$ underwent thyroidectomy. Charlson score was 0 in $81 \%$ of cases and the commonest morbidities were hypertension (14.4\%), asthma (7\%), smoking (5.6\%) and diabetes (5.1\%). Most patients underwent hemithyroidectomy (51\%) or total thyroidectomy (32\%). The indications for surgery were benign thyroid disease (52.5\%), benign inflammatory thyroid disease (21\%) and malignancy (17\%). Adjuvant radiation treatment was given to $11 \%$ of patients including $60 \%$ of patients with thyroid malignancy (Table 1).

\section{National thyroidectomy trends}

The number of thyroidectomies increased from 6789 cases in 2004 to 9085 in 2012. Taking population growth over the same period into account, activity grew by an annual average rate of $+2.9 \%$. Surgery for malignancy grew at a rate of $+6.9 \%$ and surgery for benign 
thyroid diseases showed a sustained decline between 2009 and 2012 (Figure 3). There was clear evidence of increasing specialisation of thyroid surgery: in 2004 a patient was as likely to have a thyroidectomy under the care of a surgeon performing fewer than 10 thyroidectomies per year as to have surgery performed by a surgeon undertaking over 50 thyroidectomies per year. In 2012, a patient was 4.5 times more likely to be operated on by a high-volume surgeon than by a low-volume surgeon. Furthermore, the number of uncleartype thyroidectomies, subtotal thyroidectomies and isthmusectomies fell from 1309 in 2004 to 499 in 2012 which translated to a sustained annual negative growth rate of $-11.9 \%$ (Figure $4)$.

In-hospital complications and length of stay

Overall complications rate was $6.7 \%$ and there was a slight preponderance of surgical over medical complications. In-hospital hypocalcaemia was recorded in 1488 patients $(2.05 \%)$ with the highest incidence being observed in patients undergoing thyroidectomy for thyrotoxicoses and thyroiditis, (4.34\%) followed by surgery for malignant thyroid disease (2.74\%) (Table 1). Independent risk factors for in-hospital hypocalcaemia were male sex, Charlson morbidity level $>7$, surgeon volume, where the odds ratio for surgeons performing over 75 thyroidectomies a year was 0.63 [95\% CI 0.46-0.87], and diagnosis type, with thyroid malignancy having an OR of 1.24 [95\% CI 1.02-1.50] and benign inflammatory thyroid conditions having an OR of 1.59 [1.38-1.79]. Performing concomitant neck surgery increased the OR of in-hospital hypocalcaemia to 1.49 [95\% CI 1.20-1.86].

This article is protected by copyright. All rights reserved. 
There was a sustained and significant reduction in the length of stay with increased surgeon volume. Surgeons performing over 50 thyroidectomies per year had the shortest lengths of stay. The volume effect was particularly notable for patients with higher levels of morbidity. The overall number of patients with outlying residual lengths of stay was 2804 $(3.9 \%)$ and there was a significant reduction in the proportion of length of stay outliers as surgical volume increased (Figure 5).

\section{Post-discharge complications}

Vocal palsy and hypocalcaemia that were recorded in one or more patient care episode following the index procedure occurred in $1.87 \%$ and $1.58 \%$ of patients, respectively. The main independent risk factors for post-discharge vocal palsy were patient age, male sex, burden of morbidities, surgeon volume which was consistently protective above 30, thyroid malignancy, nature of thyroidectomy performed, and whether concomitant neck surgery was undertaken. The incidence of laryngeal palsy in patients undergoing a hemithyroidectomy, which places one nerve at risk was $1.4 \%$. The incidence of laryngeal palsy in patients undergoing total or completion thyroidectomies, which place both recurrent laryngeal nerves at risk was $2.7 \%$ (relative risk $1.9 ; 95 \%$ confidence interval 1.7 2.1). The overall in-hospital mortality rate was $0.08 \%(n=59)$ and most deaths occurred in patients undergoing thyroidectomy for malignant disease (Table 2).

This article is protected by copyright. All rights reserved. 
Volume-outcome relationship

There were fewer complications as surgeon volume increased. Surgeons who performed fewer than 5 thyroidectomies per year had the highest rates of complications, mortality, or life-threatening complications. For medical complications, vocal paralysis, and death or lifethreatening complications there appeared a second peak in the incidence of complications among surgeons who performed between 20 and 29 thyroidectomies per year (Table 2 and Figure 6).

\section{DISCUSSION}

\section{Background to the present study.}

Most thyroid conditions, including most cancers, carry excellent prognoses and surgery is the mainstay of treatment for most thyroid conditions. Surgical morbidity is therefore a key determining factor in reaching treatment decisions. This has led to a drive towards offering thyroid surgery within high-volume specialist centres. We studied the national trends and patterns of thyroid surgery in England and short and long-term treatment related complications.

This article is protected by copyright. All rights reserved. 


\section{Synopsis of key findings.}

The findings of this study demonstrate that over the past decade demand for thyroid surgery has consistently outpaced the growth of the English population. This is attributable to increased surgery for thyroid cancer and for benign inflammatory thyroid conditions like Grave's disease. ${ }^{1,6}$ By contrast, surgery for benign thyroid diseases has declined. There is unambiguous evidence for increased specialisation of thyroid surgery, leading to patient benefits, which is in line with the recommendations of the Calman-Hine report, ${ }^{7}$ and which has occurred to a greater degree than in the United States. ${ }^{15}$

Complication rates were low and occurred less frequently in patients who were cared for by higher volume surgeons. There is debate over the minimum number of thyroidectomies that a surgeon should perform each year to maintain competence. Recent guidelines state that surgeons performing thyroid cancer surgery should perform a minimum of 20 thyroidectomies per year. ${ }^{16}$ We found that a higher surgical caseload was consistently associated with a reduced risk of complications, but the caseload threshold at which these protective effects emerged was different for different complications (Table 2). With vocal palsy, performing 10-19, or greater than 30 thyroidectomies a year was protective. The reason for the existence of a second vocal palsy peak at 20-29 thyroidectomies a year cannot be readily elucidated using the current data but we hypothesise that it could be due to a secondary learning curve for higher complexity cases, which surgeons performing 20-29 procedures a year may be taking on. Likewise, it is possible that surgeons performing 10-19 
thyroidectomies a year have a fairly regular but more restricted clinical practice in which high-complexity cases are not taken on. Another possible explanation is that higher surgical volumes may dilute the "trainee effect" but this cannot be further elucidated using the current dataset .

Performing more than 30 thyroidectomies a year also reduced the risk of in-hospital death or life-threatening complications, although the incidence of this composite complication was very small $(0.13 \%)$. In terms of length of stay, there was a clear volume-outcome relationship with surgeons who performed 50 or more thyroidectomies a year achieving the shortest lengths of stay. This effect was particularly marked in patients with higher levels of pre-existing morbidities (Figure 5). After adjusting for baseline conditions, the number of patients who were length of stay outliers showed a greater-than 4 -fold variation between the lowest and highest volume surgeons. There appear therefore to be different volume thresholds for different possible thyroidectomy outcomes which means that the question of the minimum annual surgeon volume needed to achieve the best outcomes will depend, to a large extent, on which outcome or outcomes are considered to be the most important. Complications and vocal palsy appear to be minimised with volumes higher than 30 with the proviso that in the latter outcome volumes 10-19 also appear protective, whilst length of stay is minimised with volumes above 50 . The choice of variable or combination of variables used for outcome assessment requires further discussion and a broad consensus.

This article is protected by copyright. All rights reserved. 


\section{Strengths and limitation of the present study.}

A strength of this study is that it includes nearly all cases of thyroid surgery in the UK and is less hindered therefore by selection, motivation and optimism biases that are inherent in voluntary data submissions collected using registry methodologies. Furthermore, it links the index operation with long-term vocal and hypercalcaemic complications beyond the time period of voluntary audits and irrespective of whether the complications were observed in the same or at another hospital. The dataset also contains information about patient morbidities which are not collected in the current national audit.

Conversely however, the study is limited by the intrinsic subjectivity, variability and error within the coded dataset ${ }^{17}$ and in particular issues concerning nature and consistency of definitions. For example, the incidence of postoperative hypocalcaemia in patients undergoing total thyroidectomy within the national audit was $27.3 \%{ }^{10}$ and we found an incidence of $5.2 \%$ in patients undergoing total thyroidectomy. This most likely relates to differences in definition. The current national audit defines hypocalcaemia as first-day adjusted calcium level of $<2.10 \mathrm{mmolL}^{-1}$ or ionised calcium level of $<1.2 \mathrm{mmolL}-1$ with no reference to development of clinical symptoms. ${ }^{10}$ A clinician completing a registry audit would complete this field based on postoperative calcium levels. A coder however would look through the clinical records and look for the condition being documented by the clinical team. We have previously shown that the particular subset of diagnoses where the diagnosis can be inferred from numerical results are subject to significant subjectivity, 
variability and error since clinical coders cannot infer a diagnosis from numbers alone. ${ }^{18}$ It is possible to produce local and national coding policies to enable the coders to equate posttreatment blood calcium levels with the diagnosis of Postprocedural Hypoparathyroidism (E892).

A further issue concerns definition of postoperative late vocal palsy. The national audit identifies a strong correlation between the incidence of post-thyroidectomy laryngoscopy and the reported incidence of immediate postoperative vocal palsy. ${ }^{10}$ We identified the condition not only by the ICD-10 code J380 (Paralysis of vocal cords and larynx), but also by signatures of clinical activity that would surround a vocal palsy. For example, if a patient had a diagnosis of vocal palsy and immediate medialisation or nerve repair was also undertaken, a vocal palsy was assigned. This logic was put in place to differentiate between postoperative vocal palsy and paresis. If the patient had an arytenoidectomy or medialisation thyroplasty at any hospital following thyroidectomy, the diagnosis of vocal palsy was assigned. Moreover, if a patient was seen two or more times by a speech and language therapist after a thyroidectomy, but not in the 18 months leading up to thyroidectomy, the diagnosis was inferred. This approach would increase the sensitivity of detecting vocal palsy, but in so doing it makes certain assumptions about correspondence of treatments most likely directed towards vocal palsy, with the existence of the condition. These assumptions would need to be further verified through local studies. This approach also determined the choice of study period as outpatients attendances were introduced to the administrative dataset in 2003, and we wished to have at least two years of follow-up to 
identify late speech therapy or surgical activity to identify vocal palsy. The study period was therefore between 2004 and 2012.

\section{Conclusion.}

In conclusion, we have performed an $N=n e a r-a l l$ study of the surgical treatment of thyroid surgery in England. We found an expanding surgical discipline that is becoming increasingly specialised and is being undertaken by high-volume surgeons whose patients suffer fewer complications and have shorter lengths of stay than those patients who are cared for by the diminishing pool of occasional thyroid surgeons.

\section{ACKNOWLEDGEMENTS}

All authors who contributed to the manuscript are included in the authorship.

\section{COMPETING INTEREST}

SE Middleton is the Director of Innovation for Dr Foster Ltd, a health information analytics company which undertakes commercial analyses of HES data. SAR Nouraei has undertaken paid and unpaid consultancy work in the field of health informatics and data quality improvement and is the architect of a range of software solutions and methodologies within this field.

This article is protected by copyright. All rights reserved. 


\section{FUNDING STATEMENT}

This research received no specific grant from any funding agency in the public, commercial or not-for-profit sectors. The Dr Foster Unit at Imperial College is largely funded by a research grant from Dr Foster Intelligence, an independent healthcare information company.

\section{REFERENCES}

1. Zevallos J.P., Hartman C.M., Kramer J.R., Sturgis E.M. \& Chiao E.Y. (2015) Increased thyroid cancer incidence corresponds to increased use of thyroid ultrasound and fine-needle aspiration: a study of the Veterans Affairs health care system. Cancer. 121, 741-746.

2. Perros P., Boelaert K., Colley S. et al. (2014) Guidelines for the management of thyroid cancer. Clin Endocrinol (Oxf). 81 Suppl 1, 1-122.

3. Sun J., Cai J. \& Wang X. (2014) Real-time ultrasound elastography for differentiation of benign and malignant thyroid nodules: a meta-analysis. J Ultrasound Med. 33, 495-502.

4. Qu N., Shi R.L., Ma B., Gao Y., Wang Y. \& Ji Q.H. (2015) The Prediction of Sonographic features and BRAF Mutation for Central Lymph Node Metastasis in Papillary Thyroid Microcarcinoma: Reply. World J Surg.

5. Coyne C., Afkhami M., Karunamurthy A. et al. (2015) Histopathologic and Clinical Characterization of Thyroid Tumors Carrying the BRAF K601E Mutation. Thyroid.

6. Li N., Du X.L., Reitzel L.R., Xu L. \& Sturgis E.M. (2013) Impact of enhanced detection on the increase in thyroid cancer incidence in the United States: review of incidence trends by socioeconomic status within the surveillance, epidemiology, and end results registry, 1980-2008. Thyroid. 23, 103-110.

7. The Expert Advisory Group on Cancer to the Chief Medical Officers of England and Wales (1995) A policy framework for commissioning cancer services. Department of Health, London.

8. Department of Health (2000) The NHS Cancer plan: a plan for investment, a plan for reform. Department of Health, London.

9. http://www.baets.org.uk/audit/.

10. Chadwick D., Kinsman R. \& Walton P. (2012) The British Association of Endocrine and Thyroid Surgeons: Fourth National Audit Report. Dendrite Clinical Systems Ltd, Henley-on-Thames.

This article is protected by copyright. All rights reserved. 
11. World Health Organization (1994) International Statistical Classification of Diseases and Related Health Problems (ICD-10). 10 edn. World Health Organization, Geneva.

12. NHS Connecting for Health (2011) OPCS Classification of Interventions and Procedures. The Stationary Office, Norwich.

13. Bottle A. \& Aylin P. (2011) Comorbidity scores for administrative data benefited from adaptation to local coding and diagnostic practices. J Clin Epidemiol, 1426-1433.

14. Tukey J.W. (1977) Exploratory data analysis. Addison-Wesley Publishing Company, Reading: Mass.

15. Loyo M., Tufano R.P. \& Gourin C.G. (2013) National trends in thyroid surgery and the effect of volume on short-term outcomes. Laryngoscope. 123, 2056-2063.

16. National Cancer Peer Review (2013) Manual for Cancer Services: Head and Neck Measures (14324). National Cancer Action Team, London.

17. Nouraei S.A., Hudovsky A., Frampton A.E. et al. (2015) A Study of Clinical Coding Accuracy in Surgery: Implications for the Use of Administrative Big Data for Outcomes Management. Ann Surg. 261, 1096-1107.

18. Nouraei S.A.R., Hudovsky A., Virk J.S., Chatrath P. \& Sandhu G.S. (2013) An audit of the nature and impact of clinical coding subjectivity variability and error in otolaryngology. Clin Otolaryngol. 38, 512-524.

\section{FIGURE LEGENDS}

Figure 1. The informatics algorithm used to identify thyroid surgery activity within the administrative dataset.

Figure 3. National trends in thyroid surgery by treating specialty.

Figure 3. National trends in the type of thyroid disease for which patients underwent thyroidectomy.

This article is protected by copyright. All rights reserved. 
Figure 4. Type of thyroidectomy as a function of year of operation and surgeon volume.

Figure 5. Treatment-related complications and post-procedure mortality as a function of surgeon volume.

Figure 6. Impact of surgeon volume on length of stay. The top graph shows the impact of surgeon volume on length of stay overall, and on length of stay as a function of the burden of morbidities. There were statistically significant differences $(\mathrm{p}<0.0001$; Analysis of Variance) between lengths of stay in different volume groups, both overall and for each of the morbidity levels. The bottom graph represents the proportion of patients with outlying lengths of stay as a function of surgeon volume. For the purposes of this analysis, a multiple regression model was constructed to calculate predicted lengths of stay. For the purposes of this and other models, variables were defined in the following way: Age at surgery was divided into bins of (<19 -reference-, 19-29,30-39, 40-49...79+). Charlson morbidity levels were divided into 0 (reference), 1-6, 7-12, 13-18 and 19+. Surgeon volume was divided into $<5$ (reference, 5-9, 10-19, 20-29, 30-49, 50-75 and 75+. Thyroid diagnoses were classified as benign (reference), benign inflammatory, benign neoplasm and malignant neoplasm. Type of thyroidectomy was aggregated into isthmusectomy/unclear-type thyroidectomy (reference), hemithyroidectomy or subtotal thyroidectomy, and total or completion thyroidectomy. Neck surgery (neck dissection or cervical lymph node sampling) performed at or within 120 days of index thyroidectomy was considered with the index procedure. Length of stay was predicted from the following multiple regression equation: Predicted 
Length of Stay $($ LoS $)=0.36+(0.08 \pm 0.01) \times A g e+(0.01 \pm 0.02) \times \operatorname{Sex}+(0.29 \pm 0.03) \times$ Burden of morbidities $+(0.10 \pm 0.01) \times$ Social Deprivation $+(0.49 \pm 0.05) \times$ Number of emergency admissions in the previous 12 months $-(0.03 \pm 0.01) \times$ Thyroid diagnosis type $+(0.29 \pm 0.01) \times$ Type of thyroidectomy + $(0.62 \pm 0.08) \times$ Neck surgery $+(4.18 \pm 0.55) \times$ Medical complications $+(2.81 \pm 0.31) \times$ Surgical complications $+(2.61 \pm 0.21) \times$ Disease-specific complications. Underlined variables were statistically significant predictors of length of stay. Actual length of stay was subtracted from predicted length of stay and Tukey's method ${ }^{14}$ for outlier detection was used to identify patients with outlier residual lengths of stay. The proportion of patients with outlying lengths of stay was calculated for each surgeon volume. Comparison using Kruskall-Wallis test showed highly significant differences between different surgical volumes and the table within the graph represents pairwise comparisons between different volume groups (Odds Ratio [95\% confidence interval]).

Table 1. Patient and treatment characteristics.

Table 2. Independent risk-factors for occurrence of post-thyroidectomy complications.

This article is protected by copyright. All rights reserved. 
Table 1. Patient and treatment characteristics.

\begin{tabular}{|c|c|c|c|c|c|c|}
\hline & $\begin{array}{l}\text { Benign } \\
\text { thyroid } \\
\text { neoplasms }\end{array}$ & $\begin{array}{l}\text { Benign } \\
\text { thyroid } \\
\text { diseases }\end{array}$ & $\begin{array}{l}\text { Benign } \\
\text { Inflammatory } \\
\text { thyroid diseases }\end{array}$ & $\begin{array}{l}\text { Malignant } \\
\text { thyroid } \\
\text { neoplasms }\end{array}$ & Overall & p-value \\
\hline Number of patients & 6912 & 38126 & 15179 & 12377 & 72594 & \\
\hline Age (years+SD [range]) & $48+15[2-93]$ & $52+39[2-97]$ & $44+15[4-92]$ & $49+17[2-98]$ & $49+30[2-98]$ & $<0.001$ \\
\hline Male sex & $1339(19)$ & $6282(16)$ & $2059(14)$ & $3228(26)$ & $12908(18)$ & $<0.0001$ \\
\hline $\begin{array}{l}\text { Emergency hospitalisation } \\
\text { within the previous year }\end{array}$ & $480(6.9)$ & $3195(8.4)$ & $1802(11.9)$ & $1138(9.2)$ & $6615(9.1)$ & $<0.0001$ \\
\hline $\begin{array}{l}\text { Year of thyroidectomy } \\
2004 \\
2005 \\
2006 \\
2007 \\
2008 \\
2009 \\
2010 \\
2011 \\
2012\end{array}$ & $\begin{array}{l}697(10.3) \\
664(9.5) \\
798(10.2) \\
726(9.3) \\
720(9.1) \\
778(9.2) \\
837(9.5) \\
844(9.4) \\
848(9.3)\end{array}$ & $\begin{array}{l}3685(54.3) \\
3777(53.8) \\
4209(53.9) \\
4136(53) \\
4279(54.1) \\
4585(54.2) \\
4592(52.3) \\
4489(50.2) \\
4374(48.1)\end{array}$ & $\begin{array}{l}1392(20.5) \\
1505(21.5) \\
1566(20) \\
1642(21) \\
1644(20.8) \\
1709(20.2) \\
1782(20.3) \\
1904(21.3) \\
2035(22.4)\end{array}$ & $\begin{array}{l}1015(15) \\
1070(15.3) \\
1238(15.8) \\
1307(16.7) \\
1260(15.9) \\
1387(16.4) \\
1573(17.9) \\
1699(19) \\
1828(20.1)\end{array}$ & $\begin{array}{l}6789 \\
7016 \\
7811 \\
7811 \\
7903 \\
8459 \\
8784 \\
8936 \\
9085\end{array}$ & $<0.0001$ \\
\hline $\begin{array}{l}\text { Morbidities } \\
\text { Hypertension } \\
\text { Hyperlipidaemia } \\
\text { Diabetes } \\
\text { Current smoking } \\
\text { Ischaemic heart disease } \\
\text { Heart failure } \\
\text { Peripheral vascular disease } \\
\text { Cerebrovascular disease } \\
\text { Cardiac arrhythmias } \\
\text { Asthma }\end{array}$ & $\begin{array}{l}827(12) \\
134(1.9) \\
236(3.4) \\
366(5.3) \\
78(1.1) \\
11(0.2) \\
108(1.6) \\
9(0.1) \\
96(1.4) \\
433(6.3)\end{array}$ & $\begin{array}{l}6293(16.5) \\
1102(2.9) \\
2243(5.9) \\
1836(4.8) \\
710(1.9) \\
101(0.3) \\
781(2) \\
66(0.2) \\
733(1.9) \\
2689(7.1)\end{array}$ & $\begin{array}{l}1556(10.3) \\
279(1.8) \\
632(4.2) \\
1290(8.5) \\
161(1.1) \\
44(0.3) \\
228(1.5) \\
20(0.1) \\
328(2.2) \\
1156(7.6)\end{array}$ & $\begin{array}{l}1800(14.5) \\
330(2.7) \\
590(4.8) \\
596(4.8) \\
208(1.7) \\
30(0.2) \\
206(1.7) \\
21(0.2) \\
276(2.2) \\
793(6.4)\end{array}$ & $\begin{array}{l}10476(14.4) \\
1845(2.5) \\
3701(5.1) \\
4088(5.6) \\
1157(1.6) \\
186(0.3) \\
1323(1.8) \\
116(0.2) \\
1433(2) \\
5071(7)\end{array}$ & $\begin{array}{l}<0.0001 \\
<0.0001 \\
<0.0001 \\
<0.0001 \\
<0.0001 \\
0.33 \\
<0.0001 \\
0.65 \\
0.0002 \\
0.0001\end{array}$ \\
\hline $\begin{array}{l}\text { COPD } \\
\text { Obesity } \\
\text { GORD }\end{array}$ & $\begin{array}{l}55(0.8) \\
79(1.1) \\
51(0.7)\end{array}$ & $\begin{array}{l}502(1.3) \\
630(1.7) \\
393(1)\end{array}$ & $\begin{array}{l}148(1) \\
219(1.4) \\
130(0.9)\end{array}$ & $\begin{array}{l}149(1.2) \\
183(1.5) \\
106(0.9)\end{array}$ & $\begin{array}{l}854(1.2) \\
1111(1.5) \\
680(0.9)\end{array}$ & $\begin{array}{l}0.0001 \\
0.009 \\
0.04\end{array}$ \\
\hline $\begin{array}{l}\text { Charlson comorbidity level } \\
0 \\
1-6 \\
7-12 \\
13-18 \\
19+\end{array}$ & $\begin{array}{l}5973(86.4) \\
716(10.4) \\
143(2.1) \\
53(0.8) \\
27(0.4)\end{array}$ & $\begin{array}{l}31557(82.8) \\
5064(13.3) \\
1004(2.6) \\
340(0.9) \\
161(0.4)\end{array}$ & $\begin{array}{l}12865(84.8) \\
1912(12.6) \\
265(1.7) \\
104(0.7) \\
33(0.2)\end{array}$ & $\begin{array}{l}8722(70.5) \\
1169(9.4) \\
606(4.9) \\
1512(12.2) \\
368(3)\end{array}$ & $\begin{array}{l}59117(81.4) \\
8861(12.2) \\
2018(2.8) \\
2009(2.8) \\
589(0.8)\end{array}$ & $<0.0001$ \\
\hline $\begin{array}{l}\text { Social deprivation quintile } \\
1 \text { (least deprived) } \\
2 \\
3 \\
4 \\
5 \text { (most deprived) } \\
\text { Unknown }\end{array}$ & $\begin{array}{l}1463(21.2) \\
1488(21.5) \\
1578(22.8) \\
1254(18.1) \\
1104(16) \\
25(0.4)\end{array}$ & $\begin{array}{l}7334(19.2) \\
7761(20.4) \\
7776(20.4) \\
7429(19.5) \\
7707(20.2) \\
119(0.3)\end{array}$ & $\begin{array}{l}2534(16.7) \\
2872(18.9) \\
3093(20.4) \\
3249(21.4) \\
3373(22.2) \\
58(0.4)\end{array}$ & $\begin{array}{l}2587(20.9) \\
2580(20.8) \\
2542(20.5) \\
2354(19) \\
2270(18.3) \\
44(0.4)\end{array}$ & $\begin{array}{l}13918(19.2) \\
14701(20.3) \\
14989(20.6) \\
14286(19.7) \\
14454(19.9) \\
246(0.3)\end{array}$ & $<0.0001$ \\
\hline $\begin{array}{l}\text { Type of thyroidectomy } \\
\text { Isthmusectomy } \\
\text { Thyroidectomy - unclear } \\
\text { Hemithyroidectomy } \\
\text { Subtotal thyroidectomy } \\
\text { Total thyroidectomy } \\
\text { Thyroidectomy } \rightarrow \text { completion }\end{array}$ & $\begin{array}{l}156(2.3) \\
82(1.2) \\
5900(85.4) \\
203(2.9) \\
534(7.7) \\
37(0.5)\end{array}$ & $\begin{array}{l}875(2.3) \\
726(1.9) \\
25443(66.7) \\
2399(6.3) \\
8553(22.4) \\
130(0.3)\end{array}$ & $\begin{array}{l}94(0.6) \\
400(2.6) \\
3311(21.8) \\
1898(12.5) \\
9448(62.2) \\
28(0.2)\end{array}$ & $\begin{array}{l}80(0.6) \\
177(1.4) \\
2071(16.7) \\
227(1.8) \\
5007(40.5) \\
4815(38.9)\end{array}$ & $\begin{array}{l}1205(1.7) \\
1385(1.9) \\
36725(50.6) \\
4727(6.5) \\
23542(32.4) \\
5010(6.9)\end{array}$ & $<0.0001$ \\
\hline $\begin{array}{l}\text { Cervical lymph node sampling } \\
\text { Neck dissection } \\
\text { Neck surgery (sampling+dissection }\end{array}$ & $\begin{array}{l}82(1.2) \\
59(0.9) \\
141(2)\end{array}$ & $\begin{array}{l}221(0.6) \\
165(0.4) \\
386(1.0)\end{array}$ & $\begin{array}{l}132(0.9) \\
57(0.4) \\
189(1.2)\end{array}$ & $\begin{array}{l}633(5.1) \\
2943(23.8) \\
3576(28.9)\end{array}$ & $\begin{array}{l}1068(1.5) \\
3224(4.4) \\
4292(5.9)\end{array}$ & $\begin{array}{l}<0.0001 \\
<0.0001 \\
<0.0001\end{array}$ \\
\hline Tracheostomy & $4(0.1)$ & $74(0.2)$ & $31(0.2)$ & $111(0.9)$ & $220(0.3)$ & $<0.0001$ \\
\hline
\end{tabular}




\section{Post-treatment Complications}

\begin{tabular}{|c|c|c|c|c|c|c|}
\hline Bleeding & $86(1.24)$ & $600(1.57)$ & $315(2.08)$ & $264(2.13)$ & $1265(1.74)$ & $<0.0001$ \\
\hline Return-to-operating room & $47(0.68)$ & $297(0.78)$ & $165(1.09)$ & $132(1.07)$ & $641(0.88)$ & 0.0002 \\
\hline Surgical-site complication & $8(0.12)$ & $76(0.2)$ & $37(0.24)$ & $49(0.4)$ & $170(0.23)$ & 0.0002 \\
\hline Iatrogenic complication & $6(0.09)$ & $108(0.28)$ & $53(0.35)$ & $89(0.72)$ & $256(0.35)$ & $<0.0001$ \\
\hline Acute cardiac event & $71(1.03)$ & $610(1.6)$ & $132(0.87)$ & $151(1.22)$ & $964(1.33)$ & $<0.0001$ \\
\hline Acute renal failure & $5(0.07)$ & $34(0.09)$ & $14(0.09)$ & $16(0.13)$ & $69(0.1)$ & 0.56 \\
\hline Pulmonary infections & $17(0.25)$ & $150(0.39)$ & $57(0.38)$ & $108(0.87)$ & $332(0.46)$ & $<0.0001$ \\
\hline Venous thrombo-embolism & $2(0.03)$ & $27(0.07)$ & $8(0.05)$ & $11(0.09)$ & $48(0.07)$ & 0.39 \\
\hline In-hospital hypocalcemia & $36(0.52)$ & $454(1.19)$ & $659(4.34)$ & $339(2.74)$ & $1488(2.05)$ & $<0.0001$ \\
\hline In-hospital death & $1(0.01)$ & $17(0.04)$ & $5(0.03)$ & $36(0.29)$ & $59(0.08)$ & $<0.0001$ \\
\hline Length of stay (days \pm SD) [range] & $1.81 \pm 1.56[0-28]$ & $2.31 \pm 4.44[0-397]$ & $2.79 \pm 4.90[0-368]$ & $3.36 \pm 7.14[0-246]$ & $2.54 \pm 4.95[0-397]$ & $<0.001$ \\
\hline Radiation treatment * & $108(1.6)$ & $428(1.1)$ & $107(0.7)$ & $7459(60.3)$ & $8102(11.2)$ & $<0.0001$ \\
\hline
\end{tabular}

\begin{tabular}{|c|c|c|c|c|c|c|}
\hline & $\begin{array}{l}\text { Medical } \\
\text { complications } \\
\mathrm{n}=1461(2.01 \%)\end{array}$ & $\begin{array}{l}\text { Surgical } \\
\text { complications } \\
\mathrm{n}=1638(2.26 \%)\end{array}$ & $\begin{array}{l}\text { Death or life- } \\
\text { threatening complications } \\
\mathrm{n}=93(0.13 \%)\end{array}$ & $\begin{array}{l}\text { Any } \\
\text { complication } \\
\mathrm{n}=4889(6.73 \%)\end{array}$ & $\begin{array}{l}\text { Post-discharge } \\
\text { laryngeal paralysis } \\
\mathrm{n}=1357(1.87 \%)\end{array}$ & $\begin{array}{l}\text { Post-discharge } \\
\text { hypocalcaemia } \\
\mathrm{n}=1150(1.58 \%)\end{array}$ \\
\hline \multicolumn{7}{|l|}{ Age group } \\
\hline $40-49$ & - & $2.01[1.12-3.6]$ & - & 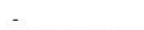 & $2.01[1.06-3.82]$ & - \\
\hline $50-59$ & $3.52[1.56-7.97]$ & $2.74[1.53-4.9]$ & - & $1.92[1.42-2.6]$ & $3.01[1.59-5.71]$ & $0.63[0.42-0.95]$ \\
\hline $60-69$ & $6.79[3.01-15.32]$ & $2.75[1.53-4.93]$ & - & $2.36[1.76-3.18]$ & $3.61[1.91-6.84]$ & $0.64[0.42-0.97]$ \\
\hline $70-79$ & $9.07[4.02-20.49]$ & $3.58[1.99-6.44]$ & 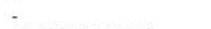 & $3.03[2.24-4.08]$ & $4.56[2.4-8.67]$ & - \\
\hline $80+$ & $15.15[6.64-34.55]$ & $5.11[2.78-9.41]$ & $11.87[1.56-90.39]$ & $4.64[3.38-6.37]$ & $5.75[2.95-11.19]$ & - \\
\hline Male sex & $1.35[1.2-1.52]$ & $1.39[1.25-1.55]$ & - & $1.19[1.11-1.28]$ & $1.16[1.02-1.32]$ & $0.68[0.58-0.81]$ \\
\hline Previous emergency admissions & $1.54[1.34-1.76]$ & - & - & $0.6[0.51-0.69]$ & - & $1.47[1.24-1.75]$ \\
\hline \multicolumn{7}{|l|}{ Charlson morbidities } \\
\hline $1-6$ & $3.23[2.83-3.69]$ & $1.35[1.17-1.55]$ & $3.77[2.15-6.61]$ & $1.73[1.6-1.88]$ & $1.43[1.23-1.66]$ & $1.21[1.02-1.44]$ \\
\hline $7-12$ & $5.9[4.95-7.02]$ & - & $2.87[1.2-6.85]$ & $2.74[2.42-3.11]$ & & - \\
\hline $13-18$ & $5.34[4.3-6.64]$ & $1.88[1.49-2.37]$ & $4.67[2.26-9.64]$ & $2.53[2.19-2.91]$ & $1.41[1.12-1.77]$ & . \\
\hline $19+$ & $7.74[5.95-10.08]$ & $2.82[2.07-3.84]$ & $11.41[5.31-24.53]$ & $3.94[3.24-4.8]$ & 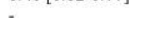 & - \\
\hline \multicolumn{7}{|l|}{ Social deprivation } \\
\hline $3^{\text {td }}$ & $1.41[1.17-1.69]$ & - & $0.31[0.14-0.66]$ & - $\quad 2 \quad+1$ & - & - \\
\hline $4^{\text {th }}$ & $1.54[1.28-1.85]$ & . & $-.110 .14=0.00]$ & $1.12[1.02-1.24]$ & . & : \\
\hline $5^{\text {th }}$ & $1.9[1.58-2.27]$ & - & . & $1.12[1.01-1.23]$ & - & . \\
\hline \multicolumn{7}{|l|}{ Annual surgeon volume } \\
\hline $5-9$ & $0.6[0.44-0.82]$ & - & - & $1.35[1.22-1.49]$ & - & - \\
\hline $10-19$ & $0.45[0.35-0.59]$ & - & - & $0.8[0.66-0.97]$ & $0.69[0.52-0.92]$ & $1.53[1.01-2.32]$ \\
\hline $20-29$ & $0.61[0.48-0.78]$ & . & - & $0.79[0.67-0.93]$ & - & 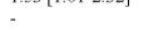 \\
\hline $30-49$ & $0.51[0.4-0.64]$ & - & $0.42[0.19-0.9]$ & $0.75[0.64-0.88]$ & $0.68[0.52-0.88]$ & - \\
\hline $50-74$ & $0.5[0.39-0.63]$ & - & $0.35[0.15-0.81]$ & $0.71[0.61-0.82]$ & $0.62[0.47-0.82]$ & . \\
\hline $75+$ & $0.57[0.45-0.71]$ & $0.67[0.51-0.87]$ & $0.21[0.08-0.52]$ & $0.69[0.59-0.8]$ & $0.63[0.48-0.83]$ & - \\
\hline \multicolumn{7}{|l|}{ Thyroid diagnosis } \\
\hline Benign inflammatory & - & $1.26[1.1-1.44]$ & - & $1.26[1.17-1.37]$ & - & $1.25[1.08-1.45]$ \\
\hline Benign neoplasm & - & - & - & $0.8[0.7-0.91]$ & $0.61[0.47-0.8]$ & $0.55[0.34-0.87]$ \\
\hline Malignant neoplasm & $0.78[0.65-0.95]$ & - & $3.37[1.83-6.23]$ & - & $1.8[1.51-2.14]$ & - \\
\hline \multicolumn{7}{|l|}{ Thyroidectomy type } \\
\hline Type unclear & . & $4.14[2.09-8.17]$ & - & $3.6[2.41-5.37]$ & $3.91[1.63-9.38]$ & $22.2[3.0-163.6]$ \\
\hline Hemithyroidectomy & - & $1.98[1.06-3.72]$ & - & $1.64[1.14-2.35]$ & $2.79[1.24-6.25]$ & \\
\hline Subtotal thyroidectomy & . & $2.99[1.56-5.72]$ & - & $2.83[1.94-4.11]$ & $2.83[1.22-6.56]$ & $17.6[2.4-126.4]$ \\
\hline Total thyroidectomy & - & $3.19[1.7-5.99]$ & - & $3.76[2.61-5.4]$ & $3.82[1.7-8.59]$ & $38.5[5.4-274.4]$ \\
\hline Completion & - & - & - & - & $3.01[1.31-6.9]$ & $18.3[2.53-132.3]$ \\
\hline Neck Surgery & - & $1.25[1.02-1.54]$ & - & $1.21[1.06-1.37]$ & $2.12[1.77-2.55]$ & $1.41[1.12-1.78]$ \\
\hline
\end{tabular}



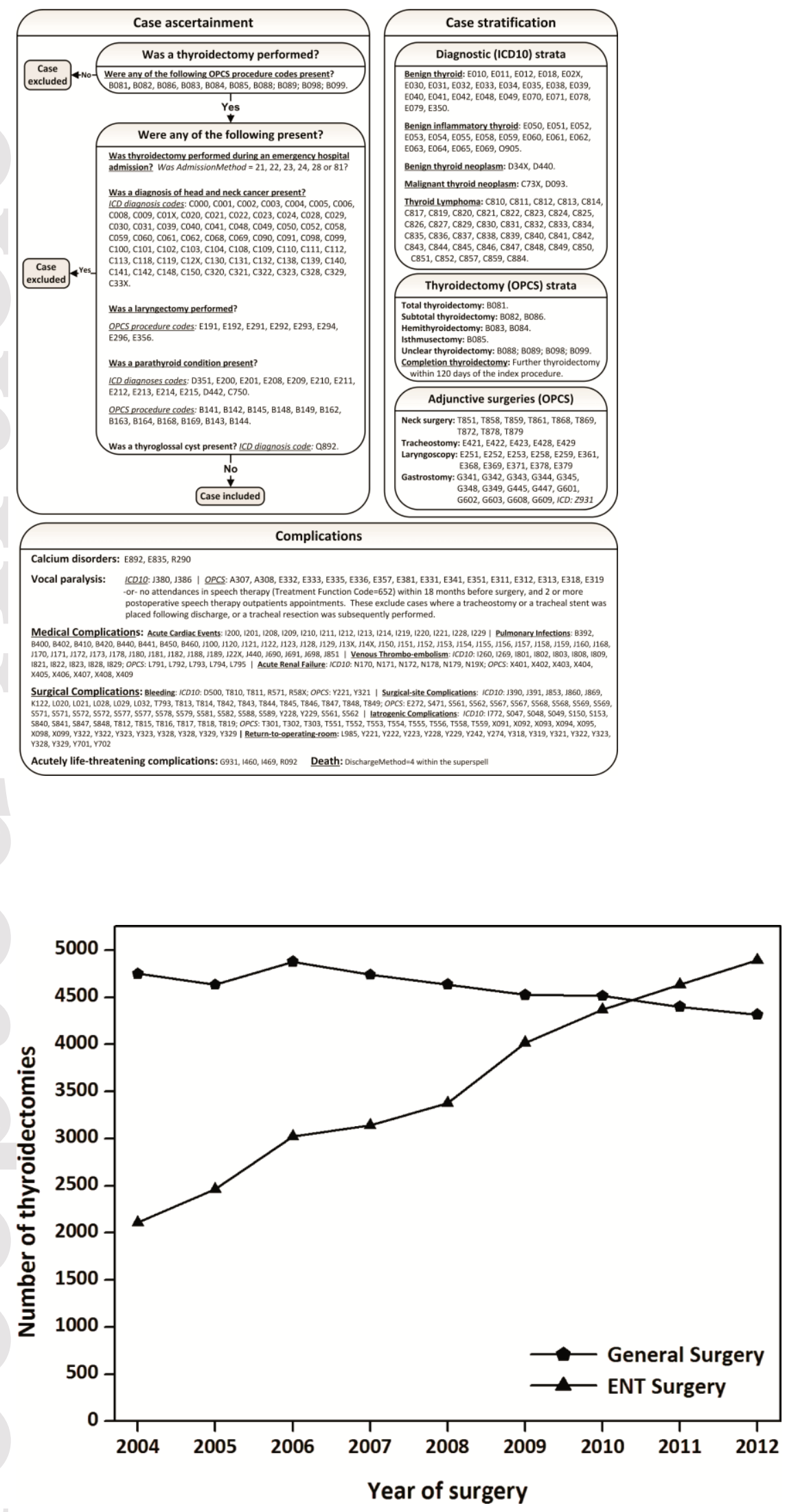

This article is protected by copyright. All rights reserved. 

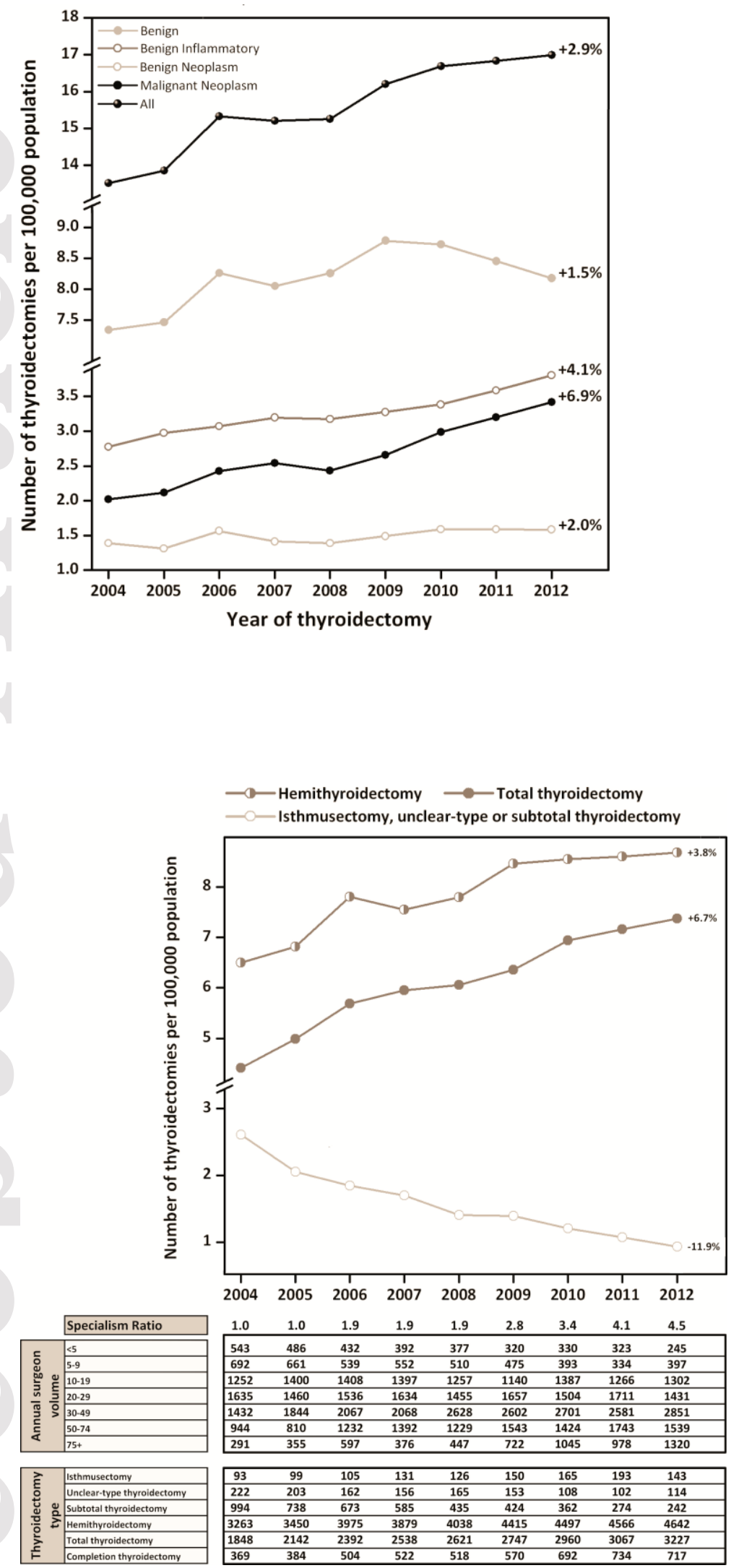

This article is protected by copyright. All rights reserved. 

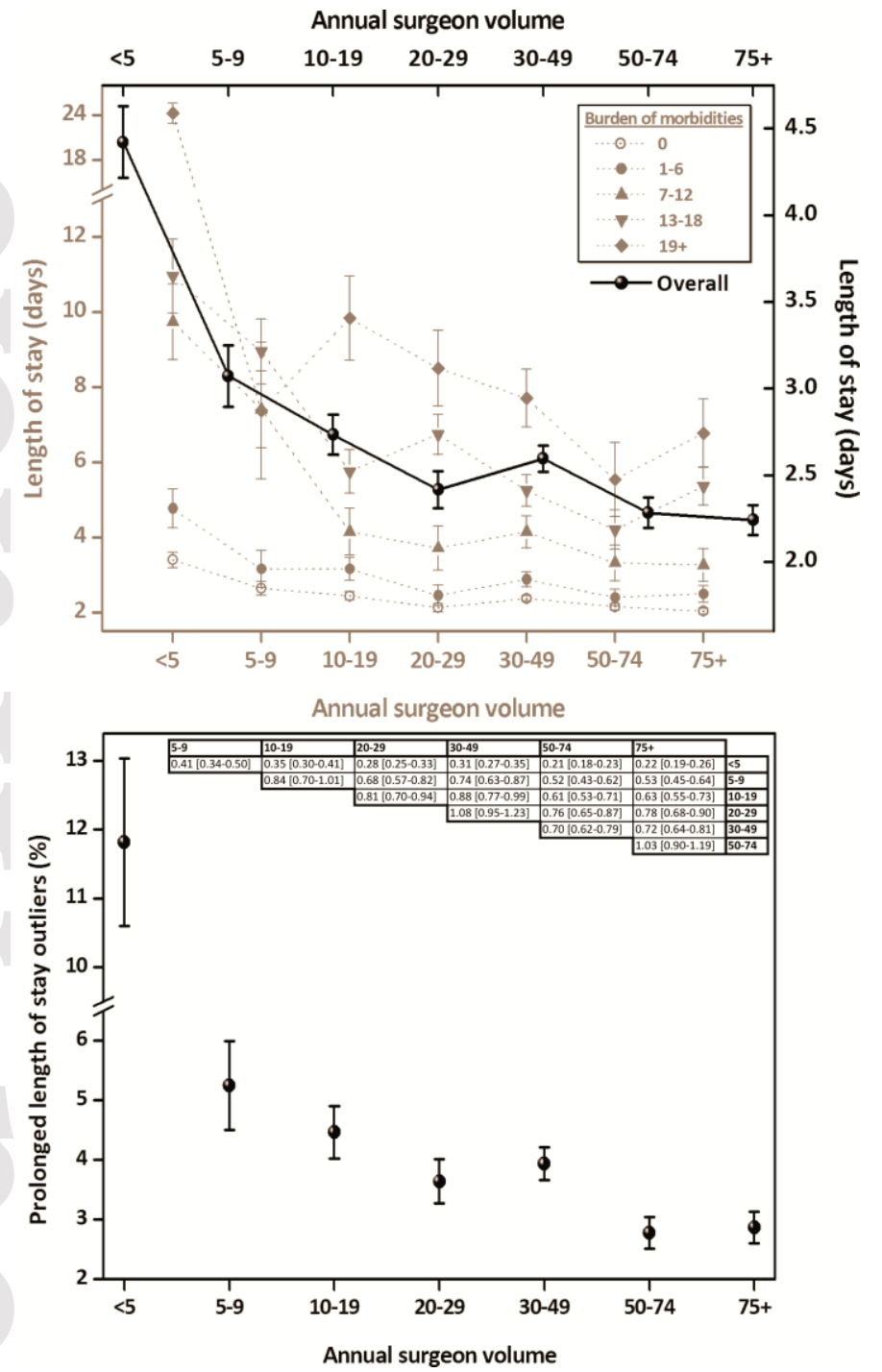

This article is protected by copyright. All rights reserved. 

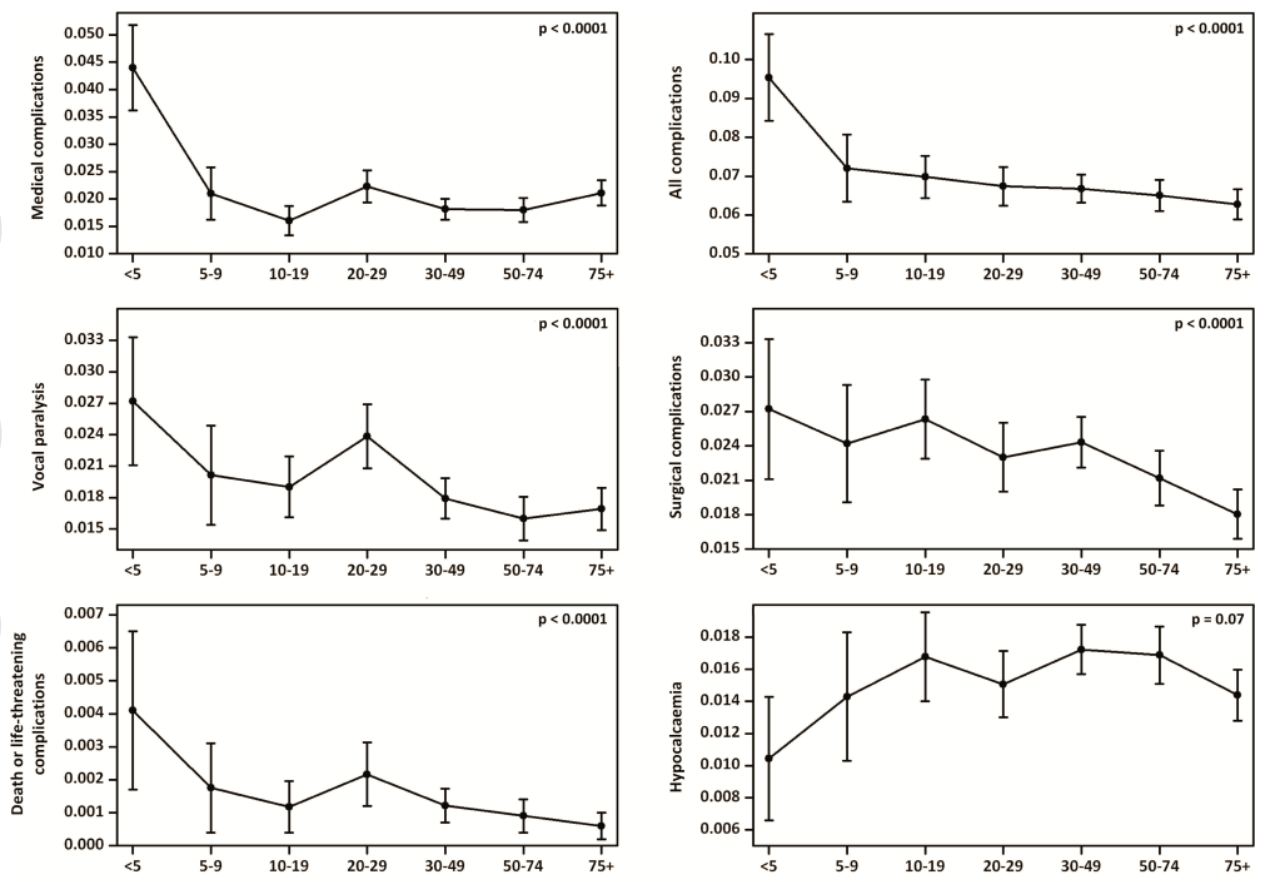

Annual surgeon volume

This article is protected by copyright. All rights reserved. 